\title{
Profile of pterygium cases seen at a tertiary referral hospital in the Philippines.
}

\author{
Archimedes Lee D Agahan ${ }^{1}$, Pius Jonas F Ocampo² \\ Department of eye sight vision centre
}

\begin{abstract}
Objective: To determine the demographic and clinical profile of pterygium cases seen at a tertiary referral hospital in the Philippines from January 2012 to October 2015.

Methods: This is a retrospective chart review. All patients were seen at the External Disease and Cornea Clinic of the Department of Ophthalmology and Visual Sciences - Philippine General Hospital (DOVS-PGH), a tertiary referral center located in Manila, Philippines. Patients' age, gender, region of origin, current address, occupation, chief complaint, pterygium type, pterygium grade and initial treatment plan were gathered. Descriptive statistics was used for analysis of patient demographics and clinical profile.
\end{abstract}

Results: Eight hundred sixty six new patients were seen and $53 \%$ were female and $47 \%$ were male. The mean age was $46.79+/-23$ years (range 11-82). There was female preponderance across all age groups except in the 21-30 year old group. Forty two percent of the patients worked outdoors, $30 \%$ work indoors, and $28 \%$ are unemployed. Most of the patients seen were born in Southern Tagalog, National Capital, Western Visayas, Bicol, and Eastern Visayas Region. Most of the patients had bilateral involvement $(\mathbf{4 9 \%})$ and the left eye is slightly more involved in unilateral cases $(26 \%$ left and $25 \%$ right). Fifteen percent of patients had bipolar pterygium and mostly involved the left eye (61\% left, $27 \%$ right, $12 \%$ bilateral). Eleven percent of the total cases seen presented as recurrent pterygium. Type 2 pterygium was the most common type, seen in $56 \%$ of patients. Grade 2 pterygium was most common, seen in $48 \%$ of patients. Appearance of a fleshy mass was the most common reason for consult $(91 \%)$. Fifty nine percent of patients underwent excision with conjunctival autograft as initial plan, $23 \%$ for excision with Mitomycin-C and conjunctivoplasty, $2 \%$ for initial Mitomycin $\mathrm{C}$ injection of pterygium and excision 1 month after and $16 \%$ of patients were for observation.

Conclusion: Pterygium continued to be a common reason for consults in our institution. Most of the pterygium patients seen were female and born in rural areas. The most common pterygium type seen is type 2. Patients working outdoors tend to have fleshy pterygium with more corneal involvement. Conjunctival autograft was the most common surgical intervention for these patients.

Keywords: Pterygium, demographics, epidemiology, Philippines.

\section{Introduction}

Pterygium is a wing-shaped, fibro vascular degeneration of the bulbar conjunctiva that grows toward and over the cornea. It may cause irregular astigmatism, visual impairment, irritation, and cosmetic problems. Dryness, inflammation, and exposure to wind and dust or other irritants may be risk factors for its development but its pathogenesis is most strongly correlated with ultraviolet exposure making it more common in tropical countries near the equeator (Agahan, 2010., Al-Bdour, 2004., Cajucom-Uy, 2010., Chen, 2015., Droutsas, 2010., Essuman, 2014., Fernandes, 2005). It has also been reported several times that increasing age, male gender, outdoor occupation, and systemic factors like hypertension are risk factors suggesting a multifactorial etiology for this condition (Gris, 2000., Küçükerdönmez, 2007., Kurna, 2013). In a systematic review and meta-analysis done by Liu et al which included 20 countries, the geographic pooled prevalence rate of pterygium was around $10 \%$ in the general population (Essuman, 2014).

Pterygium can be classified in different ways. Tan et al. classified pterygium based on its fleshiness. It is called atrophic pterygium or type 1 if the episcleral vessels are not obscured, intermediate or type 2 if fairly the vessels are fairly visible and fleshy pterygium or type 3 if the vessels are totally obscured. They reported that patients with outdoor occupation presented with fleshier types and are more likely to recur if excision with bare sclera technique was done (Lim-bon-siong, 2005., Liu, 2013). In a study done by Mahar and Manzar, they noted that a higher level of corneal involvement at presentation correlated significantly with recurrence. They graded pterygium based on the size of its corneal involvement. It is considered grade 1 if the fibrovascular proliferations involve less than $1 / 4$ of the corneal diameter, grade 2 if more than $1 / 4$ but less than $1 / 2$, and grade 
3 if it involves more $1 / 2$ of the corneal diameter and obscures the visual axis (Luanratanakorn, 2006). These classifications may help surgeons decide on what surgical technique is to be used. Simple excision with application of mitomycin-C may be used for patients with low risk for recurrence and excision with conjunctival autograft or amniotic membrane transplantation may be used for patients with a higher risk of recurrence. A combination of this two grading system with a suggested treatment plan is currently being used at External Disease and Cornea Clinic of the Department of Ophthalmology and Visual Sciences - Philippine General Hospital (DOVS-PGH) which aimed to give the best treatment option for a patient, to minimize the risk of recurrence while undergoing the least extensive procedure (Appendix 1).

Many epidemiologic studies have been done in different countries however, to our best knowledge, there has been no demographic reports done in the Philippines. It is the purpose of this study to fill the gap in knowledge of the epidemiology of pterygium patients including the identification of target population and risk factors and help establish a cost-effective preventive measure for patients at risk.

\section{Methodology}

\section{A. Study design: This study is a retrospective chart review.}

Study Population:The study population included all pterygium patients seen for the first time at the External Disease and Cornea Clinic of the Department of Ophthalmology and Visual Sciences - Philippine General Hospital (DOVS-PGH), a tertiary eye referral center, using the pterygium data collection form, from January 2012 to October 2015.

Study Procedures: Clinical charts of patients were reviewed. A standardized data-collection form previously devised by the supervising author were used Patient information such as age, gender, birthplace, chief complaint, pterygium type and grade, and treatment plan were entered into Microsoft Excel (Microsoft Corporation, Redmond, WA, USA).

Outcome Measures: The study had the following outcome measures: demographics (age, sex, geography), pterygium type and grade, and initial treatment advised.

Statistical Analysis: Descriptive statistics was used for analysis of trends in pterygium patient demographics, and epidemiologic characteristics.

\section{Results}

A total of 866 charts of pterygium patients seen in the External Disease and Cornea Clinic of the Department of Ophthalmology and Visual Sciences - Philippine General Hospital (DOVSPGH) from January 2012 to October 2015 were reviewed. Four hundred sixty one $(53 \%)$ patients were female. Most of the patients were between 30-60 years old with a range of 11-82 and a mean age of 46.79 years old. There is female preponderance across all age groups except in the 21-30 year old group (Table 1 and Figure 1)

Eight hundred forty five ( $98 \%$ of total charts reviewed) patients had their occupation logged. Of these patients, $354(42 \%)$ work outdoors, with driver $(9 \%)$ being the most common job followed by outdoor vendor $(6 \%)$, farmer $(6 \%)$, construction worker $(4 \%)$, security guard $(3 \%)$ and fisherman $(2 \%)$. Thirty percent of patients work indoor with housewife (10\%) being the most common followed by house help (3\%), teacher $(2 \%)$, sewer $(2 \%)$, cook $(2 \%)$ and launder $(2 \%)$. The remaining $28 \%$ of the population are unemployed (Figure 2).

Eight hundred seven charts (93\% of the total charts reviewed) had birthplace filled up. Most of the patients were born in region IV-A (14\%) and the National Capital Region (NCR) (14\%). Western Visayas (13\%), Bicol (12\%) and Eastern Visayas $(11 \%)$ regions were also common birthplaces seen among the pterygium patients studied.

Eight hundred fifty seven charts $(99 \%$ of the total charts reviewed) had current address filled up. Fifty six percent of patients currently live at NCR and $30 \%$ at Southern Tagalog Region (Calabarzon IV-A). Far third would be Central Luzon at 4\% (Figure 3).

Four hundred twenty one patients (49\%) had bilateral involvement. In unilateral cases, 225 (26\%) had left eye involvement and 220 (25\%) involved the right eye. Ninety-three (11\%) of the patients seen had recurrent pterygium (Figure 4$)$.

One hundred thirty two patients (15\%) had bipolar pterygium. Of these patients, 80 (61\%) had left eye involvement, 36 $(27 \%)$ had right eye involvement, and $16(12 \%)$ had bilateral involvement.

Two hundred forty one patients $(29 \%)$ had at least type 3 pterygium in one eye. Four hundred sixty three of patients $(56 \%)$ had at least pterygium type 2 in one eye. One hundred twenty patients $(15 \%)$ had type 1 pterygium. Of the 241 type 3 patients, $110(46 \%)$ work outdoors, 56 (23\%) work indoors, 62 $(26 \%)$ were unemployed, and $13(5 \%)$ had incomplete charts (Figure 5).

Eighty-three (10\%) patients had at least grade 3 pterygium. Four hundred thirteen patients $(50 \%)$ had at least grade 2 pterygium. Three hundred twenty six patients $(40 \%)$ had at least grade 1 pterygium. Of the 83 patients with grade 3 pterygium, $32(39 \%)$ patients work outdoor, 27 (33\%) patients work indoor, $22(27 \%)$ were unemployed, and $2(2 \%)$ patients had incomplete charts (Figure 6).

Seven hundred eighty five (91\%) patients consulted with a chief complaint of having a fleshy mass. Blurring of vision $(3 \%)$, foreign body sensation $(3 \%)$, itchiness $(2 \%)$, and redness $(2 \%)$ are other reasons for consult (Figure 7).

Initial plan for $513(59 \%)$ patients was excision with conjunctival autograft. Excision with intraoperative application of Mitomycin-C (MMC) was suggested for 195 patients $(23 \%)$. Injection of $\mathrm{MMC}$ one month prior to excision was suggested for 21 patients (2\%). The remaining 137 (16\%) patients were for observation (Figure 8).

\section{Discussion}

There are a lot of epidemiologic studies on pterygium 
Table 1: Summary table of the data collected.

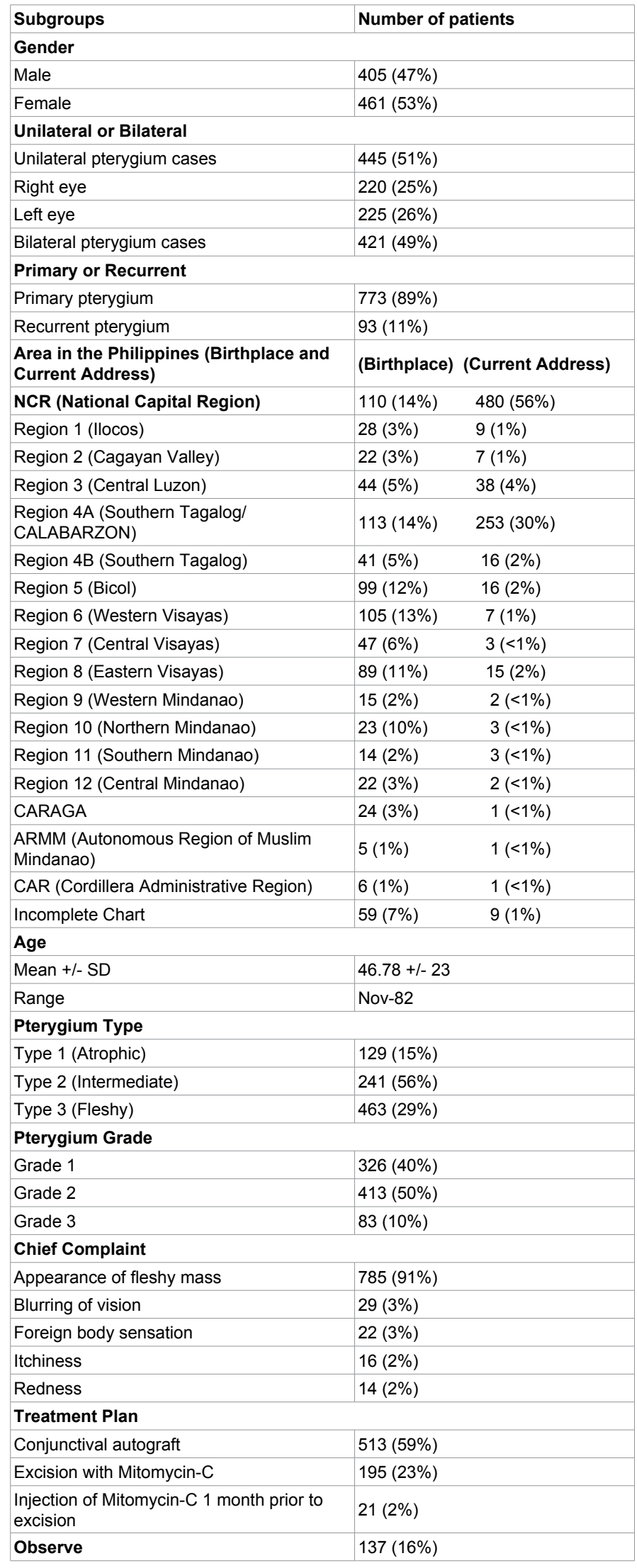

done around the world. To our knowledge, this is the first epidemiologic study in the Philippines. In this study, among the estimated 43,000 new consultations seen at the External Disease and Cornea Clinic of the Department of Ophthalmology and
Visual Sciences - Philippine General Hospital (DOVS-PGH) from January 2012 to October 2015, 866 (2\%) of them were pterygium patients referred to our clinic.

This study showed that there were more female (53\%) pterygium patients who consulted as compared to male. This is similar to the results of Lu5 but different from most of the studies done. Liu et al presented a systematic review and meta-analysis which showed that male gender was considered to be an independent risk factor (Essuman, 2014).The Philippine General Hospital, being the primary referral hospital in the Philippines, is located at the National Capital Region. This explains why most of the patients seen in this study are from NCR. Region IV-A is also a usual place of origin also because of its proximity to PGH. But important to note in this study is that patients born in the Eastern and Western Visayas and Bicol Region were also common. People born in these rural places near the sea have more daily ocular solar radiation exposure. This is an important risk factor reported in different studies (Lim-bon-siong, 2005., Lu, 2009. Lu, 2007., Mackenzie, 1992). It was reported by Chen et al that the prevalence of pterygium is higher in rural areas as compared to urban cities (Mahar, 2013).

In this study, there are more patients reported to have outdoor jobs. This was consistent with the study done by okayTaiwo et al. wherein he stated that outdoor occupation is an independent risk factor for the development of pterygium. 18 Pterygium type 3 was seen to be higher among patients working outdoors. This similar to the study done by Donald Tan stating that patients who had outdoor jobs had fleshier and more advanced type of pterygium (Liu, 2013). We also noted that an increase in corneal involvement or a higher grade of pterygium was also more common among this group of patients.

The most common chief complaint was the appearance of a fleshy mass (91\%). Cosmetic concern was the leading indication for its surgery, and thus the procedure, which gives the best cosmetic outcome and least recurrence, must be done for patients. The most common treatment plan recommended for these patients was excision with conjunctival autograft $(59 \%)$. This was the procedure that gives the best cosmetic outcome and least recurrence as shown in many studies (Marmamula, 2013., Mutlu, 1999., Nemet, 2014., okayTaiwo, 2014., Philippine General Hospital, 2015., Sánchez-Thorin, 1998). However, there was no definite protocol on what procedure would be best for patients based on pterygium type and grade since conjunctival autograft is a more extensive procedure and can also cause rare complications such as subconjunctival fibrosis at the harvest site which may lead to constricted extra ocular movement with resultant diplopia (Saw, 1999). None of the patients reviewed in this study was advised excision with amniotic membrane transplantation. This procedure was repeatedly reported to have good cosmetic outcome with minimal recurrence (Marmamula, 2013., Tan, 1997., Taylor, 2006., Threlfall, 1999., Vrabec, 1993., Wong, 2001). Thus, it must also be included in our options for the management of our patients.

\section{Conclusion}

Pterygium continued to be a common reason for consults in our institution. Most of the pterygium patients seen were female and born in rural areas. The most common pterygium type seen was 
Citation: Agahan ALD, Ocampo PJF. Profile of pterygium cases seen at a tertiary referral hospital in the Philippines. Ophthalmol Case Rep. 2017;1(1):1-7.

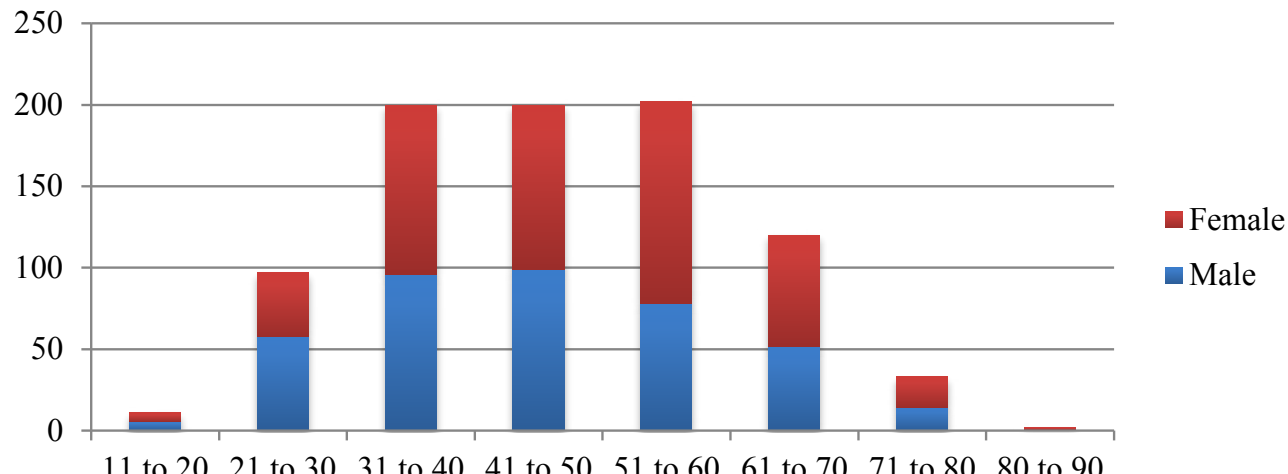

11 to 2021 to 3031 to 4041 to 5051 to $60 \quad 61$ to 7071 to 8080 to 90

Figure 1: Distribution of Patients by Age and Gender.

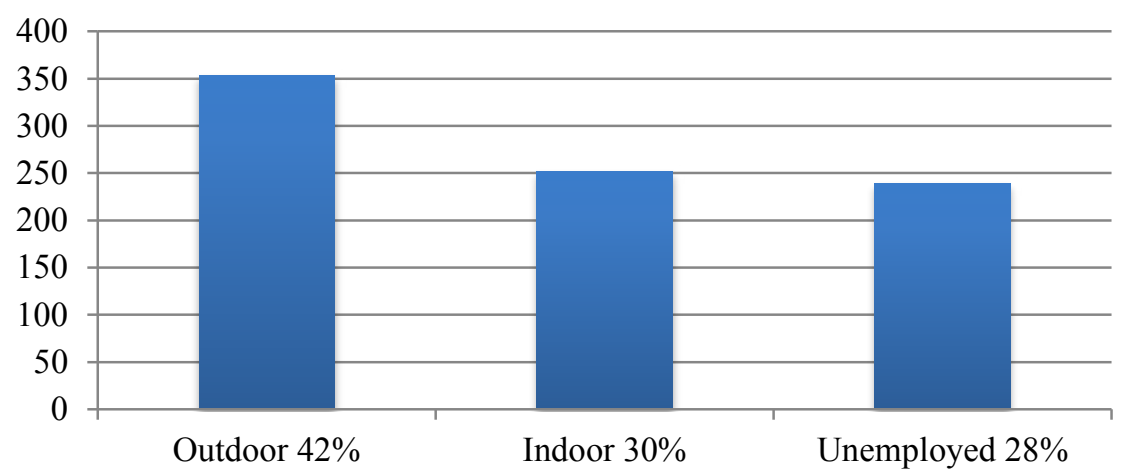

Figure 2: Occupation.

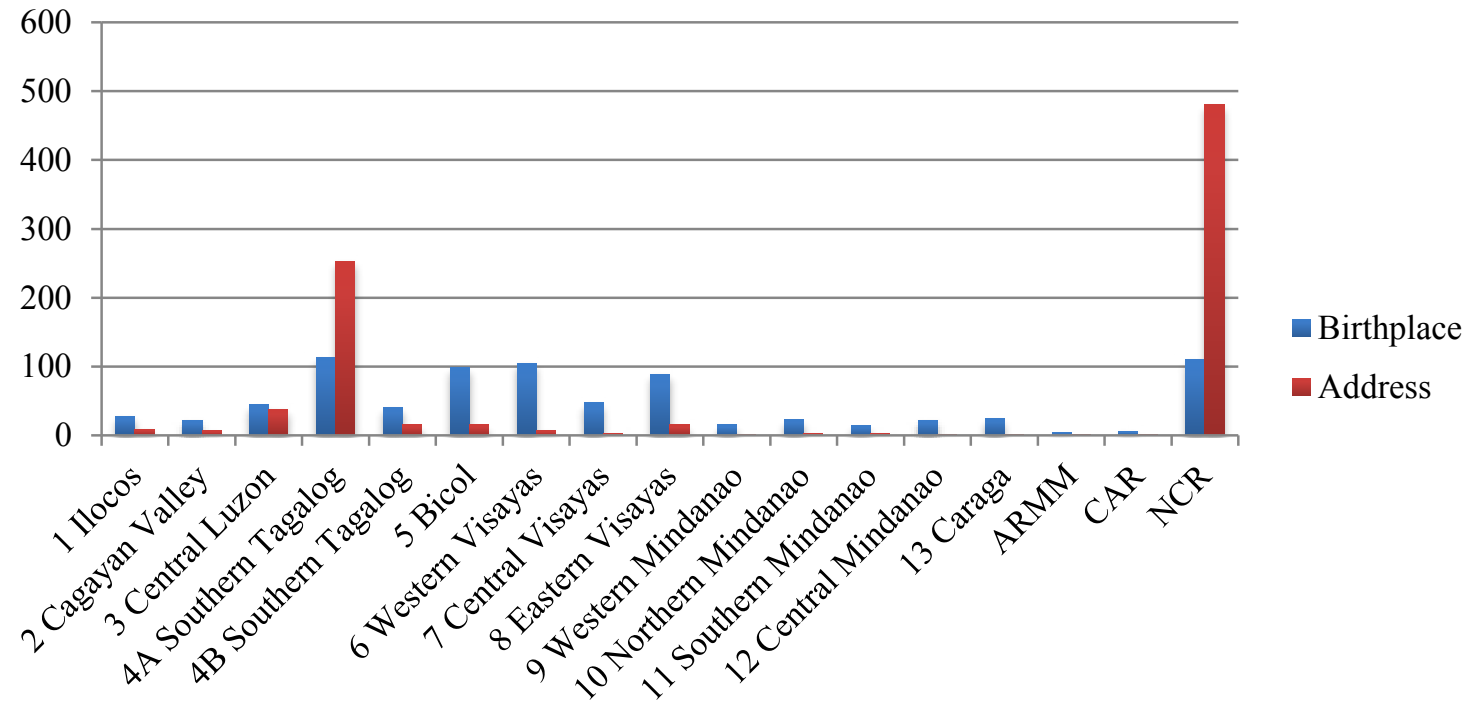

Figure 3: Birthplace and Address.

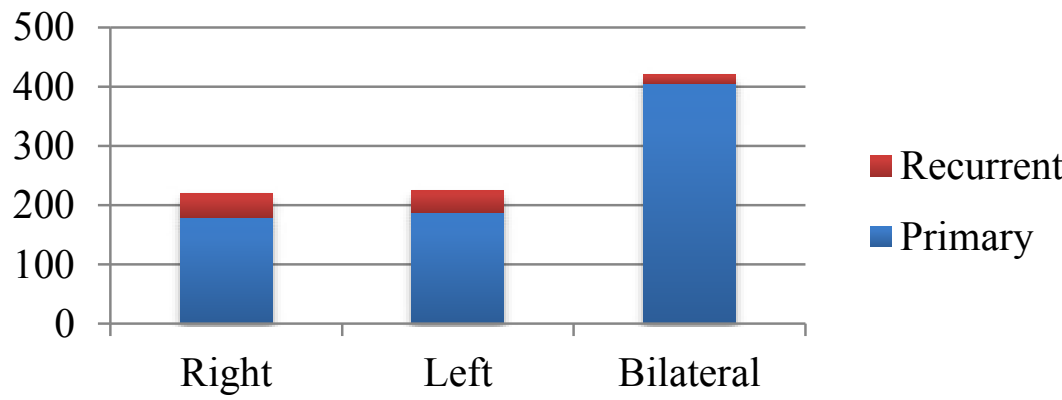

Figure 4: Laterality. 


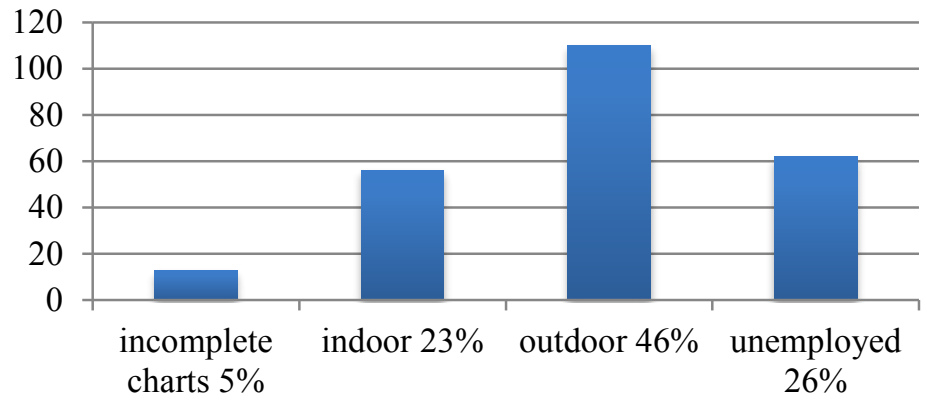

Figure 5: Occupation of Patients with Type 3 Pterygium.

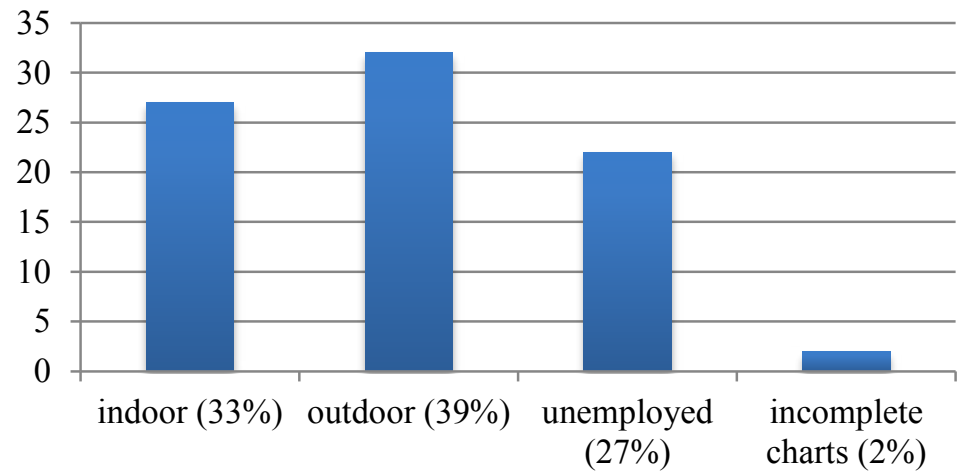

Figure 6: Occupation of Patients with Grade 3 Pterygium.
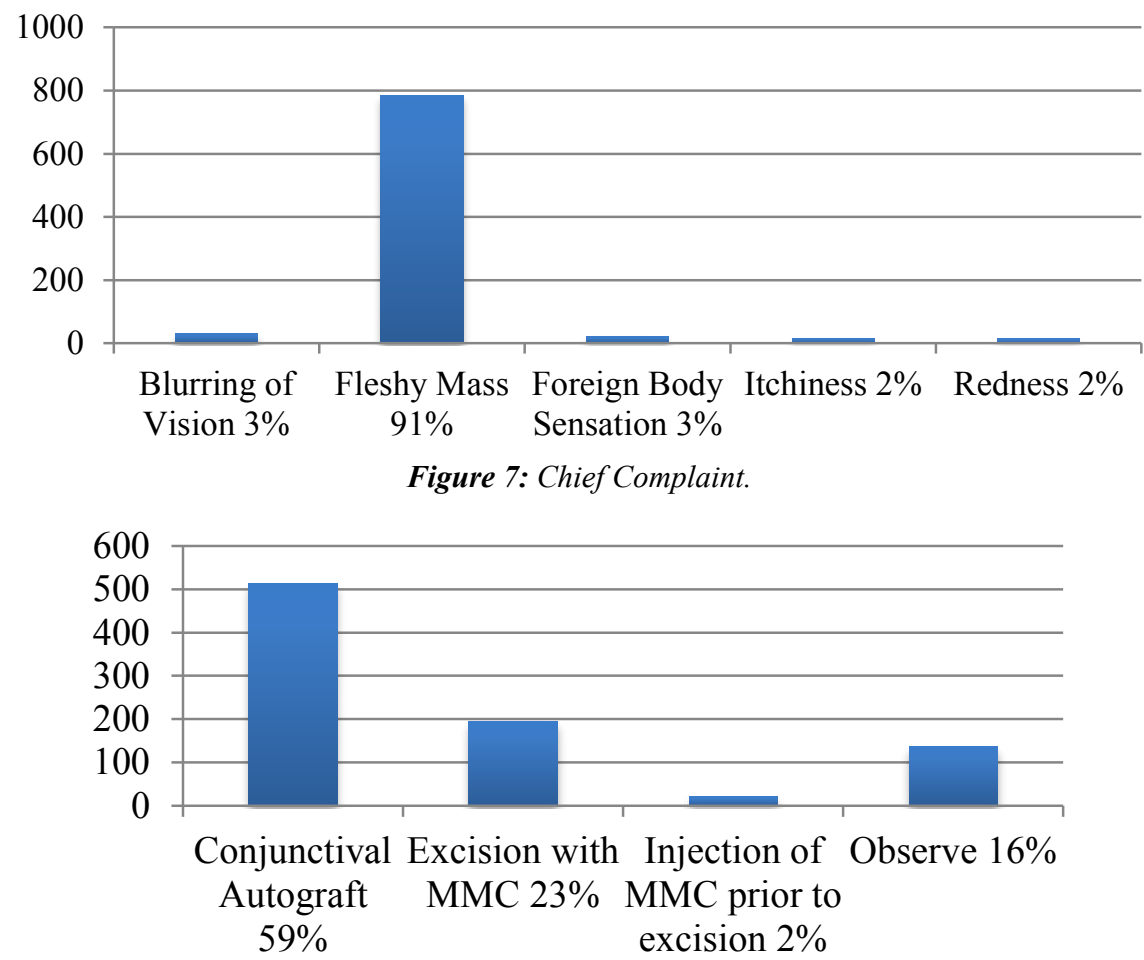

Figure 8: Treatment Plan.

type 2. Patients working outdoors tend to have fleshy pterygium with more corneal involvement. Conjunctival autograft was the most common surgical intervention for pterygium patients at DOVS-PGH.

\section{Limitations and recommendations}

Being a single-centered study in a tertiary referral hospital, selection bias was observed in the study population. It is recommended that a similar study also be done in primary institutions for better representation of the epidemiology of pterygium patients in the general population.

With approximately 10,000 new ophthalmologic consult per year, the Department of Ophthalmology and Visual Sciences of the Philippine General Hospital has a rich pool of patients and data for research. It should be reiterated to all residents and doctors the importance of having a complete chart. 
Citation: Agahan ALD, Ocampo PJF. Profile of pterygium cases seen at a tertiary referral hospital in the Philippines. Ophthalmol Case Rep. 2017;1(1):1-7.

Public health education organized to stress on the importance of UV protection especially among high-risk groups can be a very cost effective way of preventing pterygium occurrence.

An organized protocol on management of pterygium cases depending on its type, grade, patient's age and risk factors will be very beneficial to guide ophthalmologists on treatment plan to prevent recurrence and at the same time limit the cost, surgical time and need for extensive surgery.

\section{Ethical considerations}

This study was conducted after it has been approved by the University of the Philippines, Manila Research Ethics Board (UPMREB). All patient information gathered during the course of this study was kept anonymous and confidential, and was only reported as part of group data. There was no conflict of interest in any form for this study. All the expenses that arose in this research endeavor were shouldered by the principal investigator, and no additional expenses were be incurred by the participants at any time during the study.

\section{References}

1. Agahan A.L.D., Astudillo, P.P., Cruz, R.C.D. Comparative Study on the Use of Conjunctival Autograft With or Without Mitomycin-C in Pterygium Surgery. Philipp J Ophthalmol 39,2010; 73-7.

2. Al-Bdour M, Al-Latayfeh, M.M.Risk factors for pterygium in an adult Jordanian population. Acta Ophthalmol Scand. $82,64-67$.

3. Cajucom-Uy, H., Tong, L., Wong, T.Y., Tay, W.T., Saw, S.M (2010). The prevalence of and risk factors for pterygium in an urban Malay population: the Singapore Malay Eye Study (SiMES). Br J Ophthalmol. 2004; 94: 977-81.

4. Chen T, Ding L, Shan G.et al. Prevalence and racial differences in pterygium: a cross-sectional study in Han and Uygur adults in Xinjiang, China. Invest Ophthalmol Vis Sci.2010; 56: 1109-17.

5. Droutsas K, Sekundo W. Epidemiology of pterygium. A review. Ophthalmologe.2010; 107: 511-16, .

6. Essuman V.A, Ntim-Amponsah C.T, Vemuganti, G.K. Epidemiology and recurrence rate of pterygium post excision in Ghanaians. Ghana Med J. 2014; 48: 39-42.

7. Fernandes M, Sangwan V.S, Bansal A.K, et al. Outcome of pterygium surgery: analysis over 14 years. Eye (Lond).2011; 19: $1182-90$.

8. Gris O, Güell J.L, del C.Z et al .Limbal-conjunctival autograft transplantation for the treatment of recurrent pterygium. Ophthalmology. 2011;107: 270-273.

9. Küçükerdönmez C, Akova Y.A, Altinörs D.D. Comparison of conjunctival autograft with amniotic membrane transplantation for pterygium surgery: surgical and cosmetic outcome. Cornea.2012; 26: 407-13.

10. Kurna S.A, Altun A, Aksu B, et al . Comparing treatment options of pterygium: limbal sliding flap transplantation, primary closing, and amniotic membrane grafting. Eur $\mathrm{J}$ Ophthalmol. 2013; 23: 480-87.

11. Lim-bon-siong R.Dehydrated human-amniotic- membrane allograft versus conjunctival autograft after pterygium excision. Philipp J Ophthalmol. 2015; 30: 166-71.

12. Liu L, Wu J, Geng, J,et al. Geographical prevalence and risk factors for pterygium: a systematic review and metaanalysis. BMJ Open.2013; 3: 37-87.

13. Luanratanakorn P,Ratanapakorn T, Suwan-Apichonet al. randomised controlled study of conjunctival autograft versus amniotic membrane graft in pterygium excision. $\mathrm{Br}$ J Ophthalmol.2013; 90: 1476-80.

14. Lu J, Wang Z, Lu P, et al. Pterygium in an aged Mongolian population: a population-based study in China. Eye (Lond).2009; 23: 421-27.

15. Lu P, Chen X, Kang Y, et al.Pterygium in Tibetans: a population-based study in China. Clin Experiment Ophthalmol.2012; 35: 828-33.

16. Mackenzie F.D, Hirst L.W, Battistutta D, et al. Risk analysis in the development of pterygia. Ophthalmology.1992; 99: 1056-61.

17. Mahar P.S, Manzar N. Pterygium recurrence related to its size and corneal involvement. J Coll Physicians Surg Pak. 2013;23: 120-23.

18. Malhotra C, Jain A.K. Human amniotic membrane transplantation: Different modalities of its use in ophthalmology. World J Transplant. 2014; 111-21.

19. Marmamula S, Khanna,R.C. Rao. Population-based assessment of prevalence and risk factors for pterygium in the South Indian state of Andhra Pradesh: the Andhra Pradesh Eye Disease Study. Invest Ophthalmol Vis Sci. 2013;54: 5359-66

20. Mutlu F.M, Sobaci G., Tatar T. Et al . A comparative study of recurrent pterygium surgery: limbal conjunctival autograft transplantation versus mitomycin $\mathrm{C}$ with conjunctival flap. Ophthalmology. 1993;106: 817-21.

21. Nemet A.Y, Vinker S, Segal O,et al. Epidemiology and Associated Morbidity of Pterygium: A Large, CommunityBased Case-Control Study. Semin Ophthalmol.2014; 31: 1-6.

22. okayTaiwo O.A, Beki-bele, et al. Prevalence and pattern of eye disorders among commercial motorcycle riders in Ile-Ife, Osun state. Niger Postgrad Med J. 2013;21: 255-61.

23. Philippine General Hospital. Department of Ophthalmology and Visual Sciences Accomplishment Report January 2012- June 2015.

24. Sánchez-Thorin J.C, Rocha, G, Yelin, J.B. Meta-analysis on the recurrence rates after bare sclera resection with and without mitomycin $\mathrm{C}$ use and conjunctival autograft placement in surgery for primary pterygium. $\mathrm{Br} J$ Ophthalmol. 1992;82: 661-65.

25. Saw S.M, Tan D. Pterygium: prevalence, demography and risk factors. Ophthalmic Epidemiol.1993; 6: 219-28. 
26. Tan D.T, Chee S.P, Dear K.B, et al . Effect of pterygium morphology on pterygium recurrence in a controlled trial comparing conjunctival autografting with bare sclera excision. Arch Ophthalmol (Chicago, Ill 1960).1961; 115: 1235-40.

27. Taylor S.L, Coates M.L, Vallejos Q,et al. Pterygium among Latino migrant farmworkers in North Carolina. Arch Environ Occup Health. 2006;61: 27-32.
28. Threlfall T.J, English D.R. Sun exposure and pterygium of the eye: a dose-response curve. Am J Ophthalmol. 1999;128: 280-87.

29. Vrabec M.P, Weisenthal R.W, Elsing S.H. Subconjunctival fibrosis after conjunctival autograft. Cornea. 2003;12: 181-83.

30. Wong T.Y, Foster P,Johnson G.J,et al. The prevalence and risk factors for pterygium in an adult Chinese population in Singapore: the Tanjong Pagar survey. $A m ~ J$ Ophthalmol.2001; 131: 176-83.

\section{*Correspondence to:}

Archimedes Lee D Agahan

Department of eye sight vision center,

Tel: +632- 336-5203

Fax: +632-416-6701

E-mail: adagahan@up.edu.ph 